\title{
INFLUENCE OF RECYCLED FIBRES IN PAPER ON THE UV STABILITY OF THERMOCHROMIC PRINTS
}

\author{
Rahela Kulčar (D), Marina Vukoje (iD), Ivana Krajnović (D), Mirela Rožić (iD) \\ University of Zagreb, Faculty of Graphic Arts, Zagreb, Croatia
}

\begin{abstract}
Recycled paper for environmentally conscious consumers can positively influence product selection. Thermochromic inks printed on such materials can give the product a special effect and increase its market competitiveness. During recycling, the paper is subjected to the action of various processes and chemicals, which later can have an impact on its stability, structural and optical properties. As is already known, the optical properties of paper affect the quality of the print. Thus, the goal of this study is to determine whether environmentally friendly substrates containing recycled fibres can be of the same quality as non-recycled substrates for the printing of thermochromic inks. For the research purposes, two commercially available thermochromic inks were printed on papers with a certain percentage of recycled fibres (33\% and 100\%). The results will show whether the percentage of fibres affects the colorimetic properties, dynamic characteristics of thermochromic inks and the UV stability during accelerated ageing of thermochromic prints.
\end{abstract}

Key words: thermochromic inks, UV stability, recycled fibres

\section{INTRODUCTION}

Today, many different types of inks and printing processes are used. To satisfy the market innovations, there is a greater demand for traditional and functional printing inks, such as thermochromic (TC) printing inks. Thermochromism in the graphics industry has a wide range of applications and their development is still in progress (Gunde et al, 2011). Also, today's graphic designers try to use environmentally friendly substrates. Recycled paper for eco-conscious consumers can have a positive reaction during product selection. TC inks printed on such materials can give the product a special effect. In 2016, $72.5 \%$ of all paper consumed in Europe was recycled. Recovered paper is today the most important raw material for the production of paper, paperboard and corrugated board (CEPI, 2017). The quality of paper made from recycled fibres is generally lower than that of the virgin fibres due to a shorter fibre length which in the end affects the tensile strength (Coppola et al, 2018). When it comes to printing, the printing quality is strongly influenced by the structural (topography and porosity) and chemical properties of the paper surface, being one of the most important factors concerning costumer's evaluation (Koivula et al, 2008; Moutinho et al, 2011). One of the main functions of printing inks is to adhere the printing substrate and remain there for the whole lifespan of print. Adhesion of inks to paper plays an important role in many industrial applications (Awaja et al, 2009). Kibirkštis et al (2013) showed in their research that geometrical accuracy of small elements printed on recycled paper, in comparison to pictures printed on paper produced from virgin fibres, is almost the same.

Leuco dye-based thermochromic inks are today commercially available in all major ink types (such as water-based, solvent-borne and photocuring inks) for application on different substrates. Most TC organic composites are mixtures consisting of colour former (leuco dye), a developer and solvent. TC printing inks are normally protected in polymer capsules and dispersed in the resinous medium. Offset TC inks have different rheological properties to conventional ones (Kulčar et al, 2010; Friškovec et al, 2013; Panák et al, 2015). The colorimetric properties of TC inks are only retained for a rather short period. The quite short pot life and poor stability of TC colour are related to the chemical stability of the ink formulation. Attention should also be given to the substrates used since the printing substrate can dynamic properties during heating and cooling process of thermochromic ink as shown in previous research (Vukoje et al, 2018a).

The objective of this work is to determine the influence of UV stability on the dynamic properties of TC inks printed on an environmentally friendly paper substrate, but in order not to lose its quality. Also, the TC inks with different chemical compositions on such substrate will suggest a more acceptable option with an emphasis on greater lightfastness stability. 


\section{EXPERIMENTAL}

Two recycled papers with different proportions of recycled fibers (RF), 33\% (33RF) and 100\% (100RF), were used as a substrate in printing trials.

Also, two commercially available offset thermochromic (TC) inks were used for printing. TC27 offset ink was coloured in blue below its activation temperature $\left(T_{A}=27^{\circ} \mathrm{C}\right)$ and changed to colourless when was heated above the activation point. TC45 ink was coloured in green below its activation temperature $\left(T_{A}=45^{\circ} \mathrm{C}\right)$ and changed to yellow above the activation point. The solvent in the TC27 ink was a mineral spirit and TC45 ink were vegetable-based. The colour changes of both inks were reversible, i.e. original colour was restored upon cooling. Ink producers recommended printing these inks onto uncoated, absorbent papers to achieve the best print quality.

The printing trials were carried out using the Prüfbau Multipurpose Printability Tester. The quantity of 1.5 $\mathrm{cm}^{3}$ of ink was applied on the distribution rollers while printing was carried out with the printing force of $600 \mathrm{~N}$. The samples were printed in full tone.

For accelerated ageing of the prints, Solarbox 1500e device (CO.FO.ME.GRA) was used. This device enables the simulation of environmental conditions in an open or closed space and ensures the control of temperature and radiation. All the samples were exposed to filtered xenon light for a period of 6 and 12 hours at a BST temperature of $60{ }^{\circ} \mathrm{C}$, at irradiation of $550 \mathrm{~W} / \mathrm{m}^{2}$. The indoor filter was used for the simulation of conditions of internal exposure (equivalent to sun rays filtered through a windowpane). The UV filter was used to change the xenon spectral curve into the ultraviolet range.

Spectral reflectance was measured by using Ocean Optics USB2000+ spectrometer using $50 \mathrm{~mm}$ wide integrating sphere under (8: di) measuring geometry (diffuse geometry, a specular component included). The printed samples were heated/cooled on the full-cover water block (EK Water Blocks, EKWB d.o.o. Slovenia). Its temperature was varied by thermostatically controlled water block. Reflectance spectra were measured in one heating/cooling cycle. The measurements were performed in the steps of $1 \mathrm{~nm}$ for the spectral region from 430 to $750 \mathrm{~nm}$. Ocean Optics SpectraSuite software was used for the calculation of the CIELAB values from measured reflectance. The D50 illuminant and $2^{\circ}$ standard observer were applied in these calculations.

\section{RESULTS AND DISCUSSION}

The samples were measured at estimated temperatures of each thermochromic colour, and spectral curves ranging from 430 to $750 \mathrm{~nm}$ were read through the measurement to give a visual representation of the colour change at different temperatures.

Figures 1 - 3 show the spectral reflectance curves of a sample printed with TC27 printing ink, which at an activation temperature of $27^{\circ} \mathrm{C}$ goes from light blue to transparent and spectral reflections of the printing substrate on which the ink is printed. Measurements were made from $15^{\circ} \mathrm{C}-55^{\circ} \mathrm{C}$ in both directions. The results show that the effect of UV radiation leaves consequences on all samples in a relatively short time. Spectral reflectance curves additionally show the differences int the paper structures, i.e. the reflectance in the blue part of the 33RF paper spectrum indicate the presence of optical brighteners in the paper, while in the case of 100RF paper this is absent.

The results show that the decolorization of TC27 sample is not complete even at the highest temperatures applied in the experiment, which are far above the activation temperature. Also based on the spectral reflection curves, it is clearly observed that the thermochromic effect of color change with a longer time of UV aging is significantly reduced. Moreover, the paper itself is subject to change during UV aging as can be seen from the reflection curves, whose intensities decrease during exposure to UV irradiation.

Figures 4-6 show spectral reflectance curves of a sample printed with the TC45 thermochromic printing ink, which at the activation temperature of $45^{\circ} \mathrm{C}$ turns from green to yellow. Measurements were made from $10^{\circ} \mathrm{C}-60^{\circ} \mathrm{C}$ in both directions. 

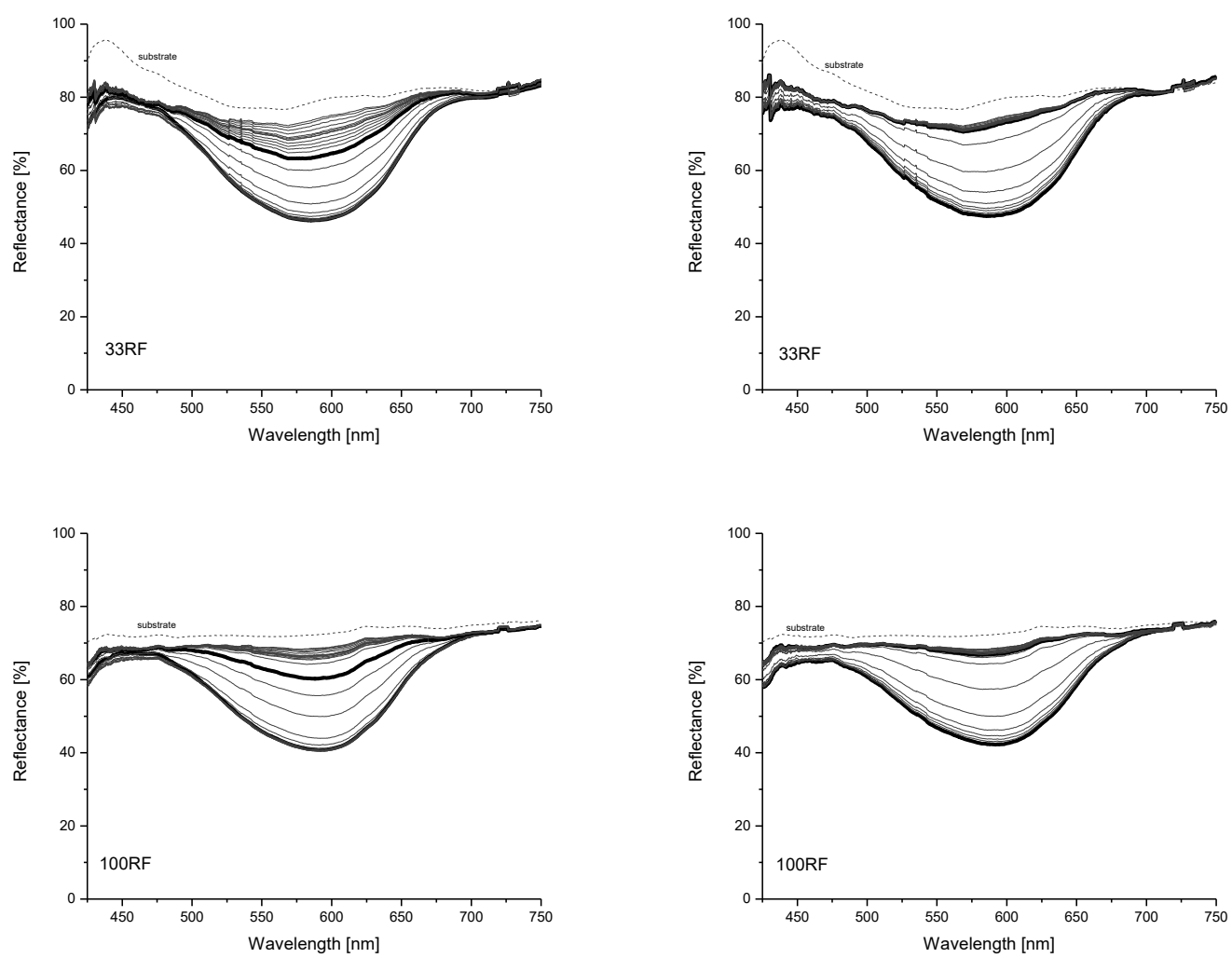

Figure 1: Spectral reflectance curves for the TC27 sample measured at heating (left) and cooling (right) on 33RF and 100RF papers
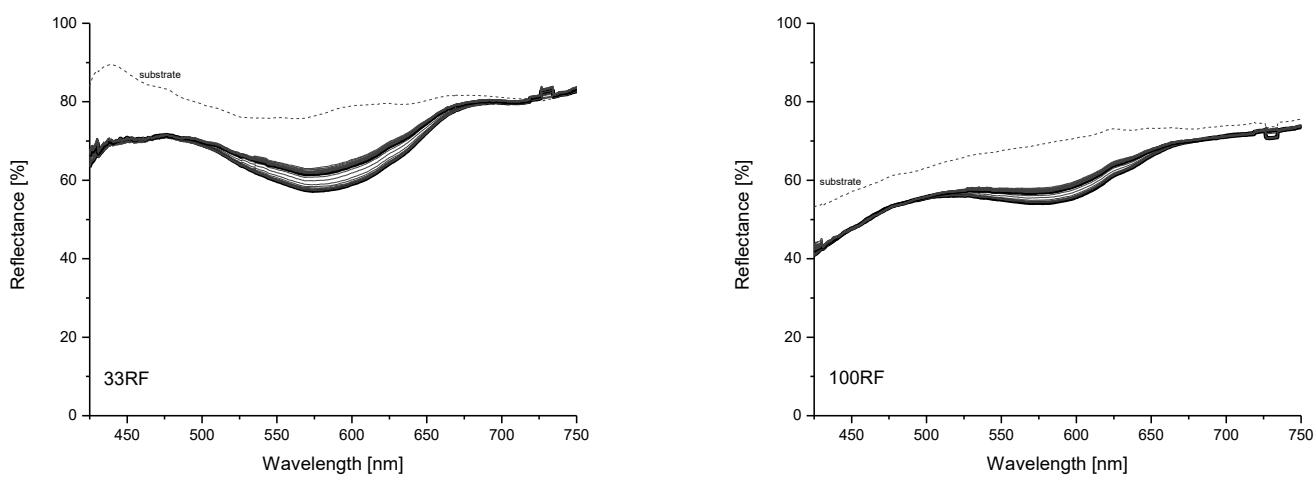

Figure 2: Spectral reflectance curves for the TC27 sample exposed to light for 6 hours (measured at heating) on different papers
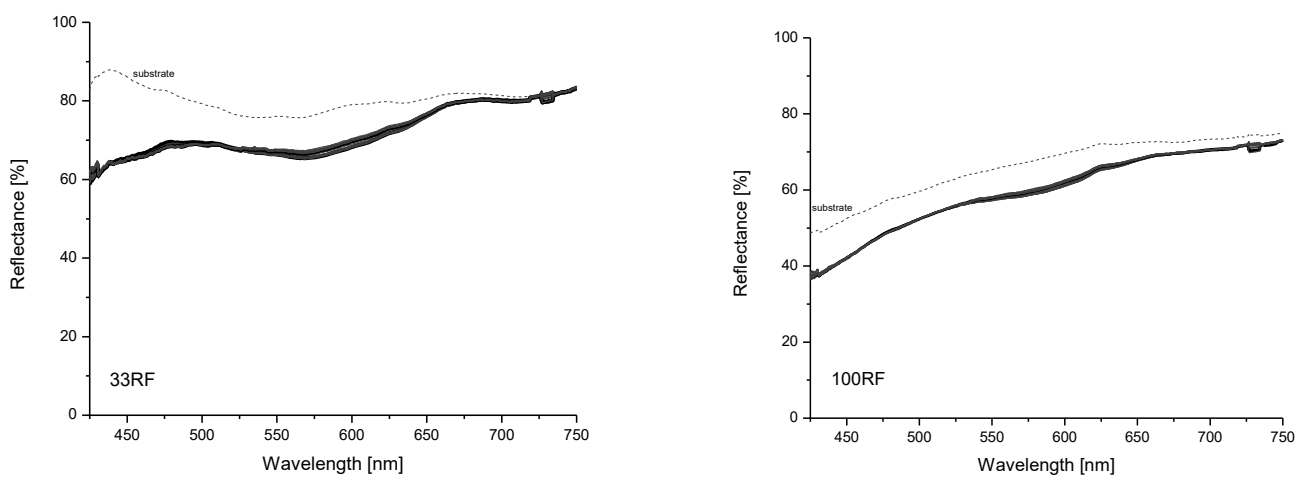

Figure 3: Spectral reflectance curves for the TC27 sample exposed to light for 12 hours (measured at heating) on different papers 

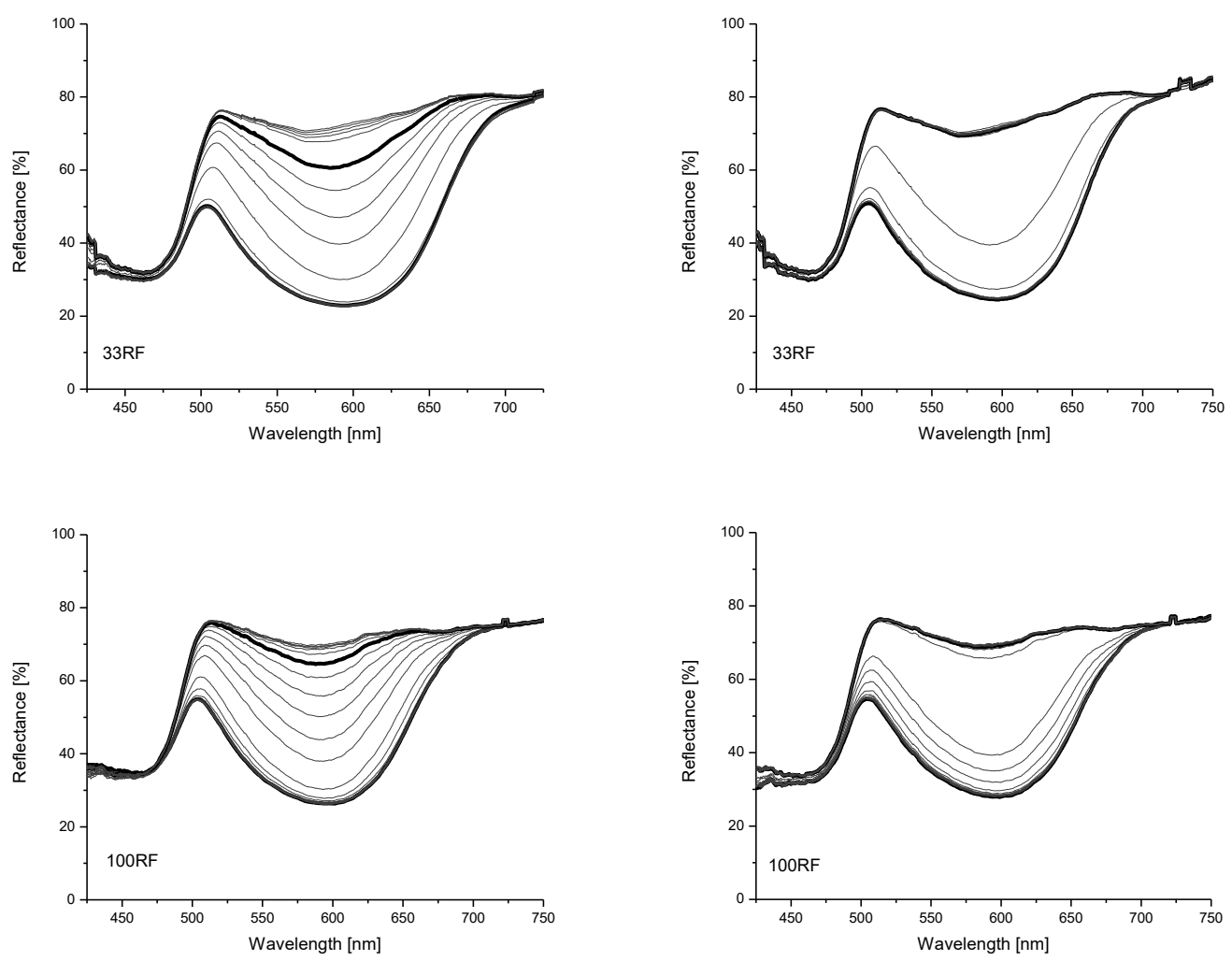

Figure 4: Spectral reflectance curves for the TC45 sample measured at heating (left) and cooling (right) on different papers
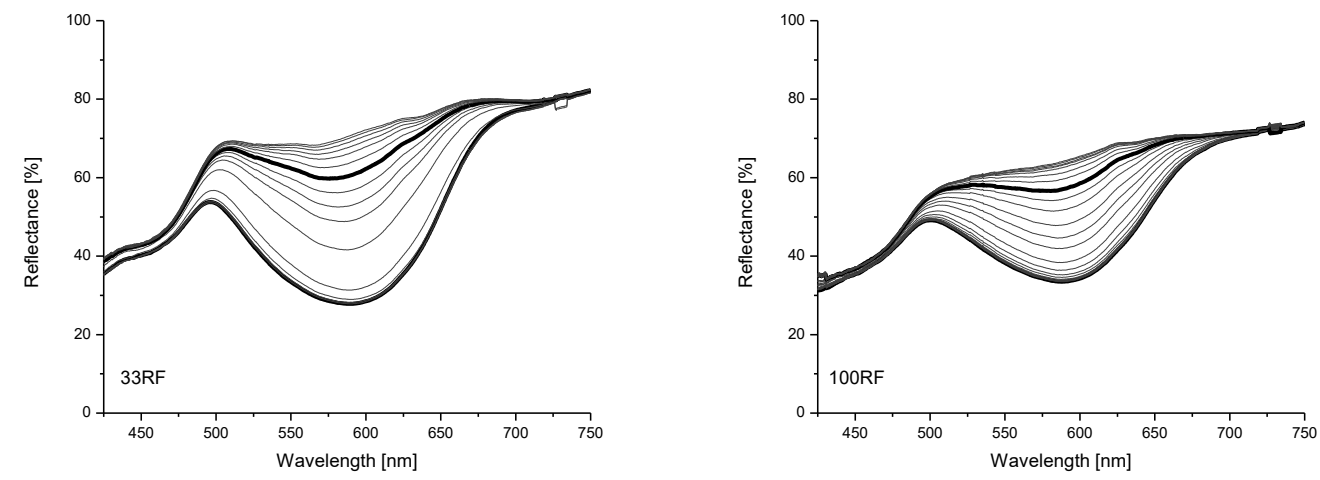

Figure 5: Spectral reflectance curves for the TC45 sample exposed to light for 6 hours (measured at heating) on different papers
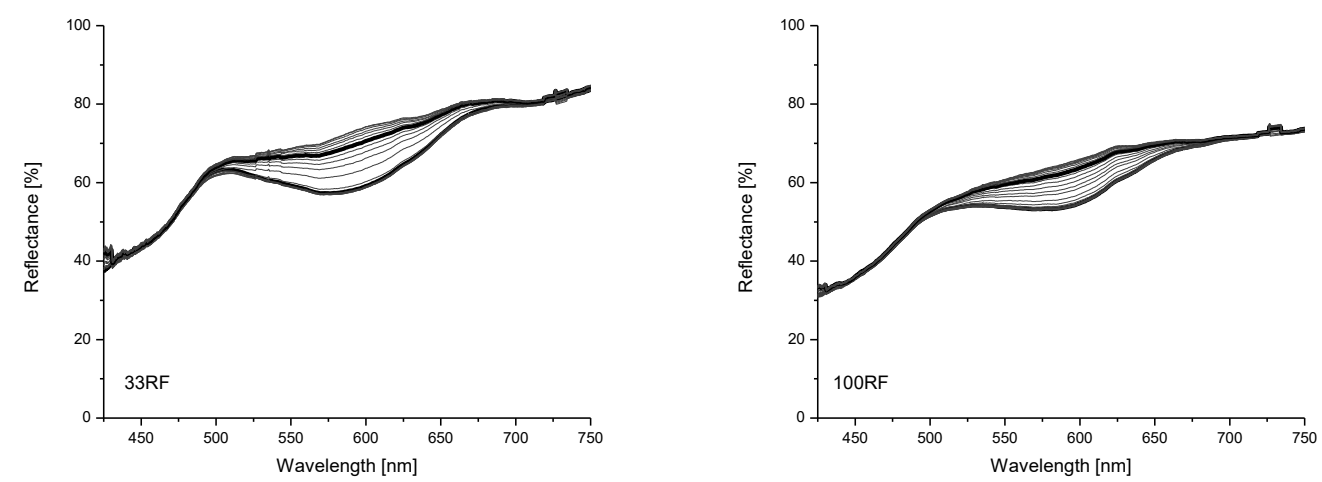

Figure 6: Spectral reflectance curves for the TC45 sample exposed to light for 12 hours (measured at heating) on different papers 
From the measured spectral reflectance curves (Figure 1-6), it can be seen that the colour change is gradual and continuous and that the spectral curves of all the samples differ when the samples are heated and cooled at the same temperature. Color degradation is approximately the same on both recycled papers. After 6 hours of ageing, only slightly changes occurred on TC45 sample on both papers while on TC27 the colour degradation is greater. Ageing decreases the dynamics of discolouration, and after 12 hours of ageing, the thermochromic effect of TC27 sample is completely lost, while on TC45 colour change is still present, which indicates that TC45 ink is more stable compared to TC27 regardless of the paper used.

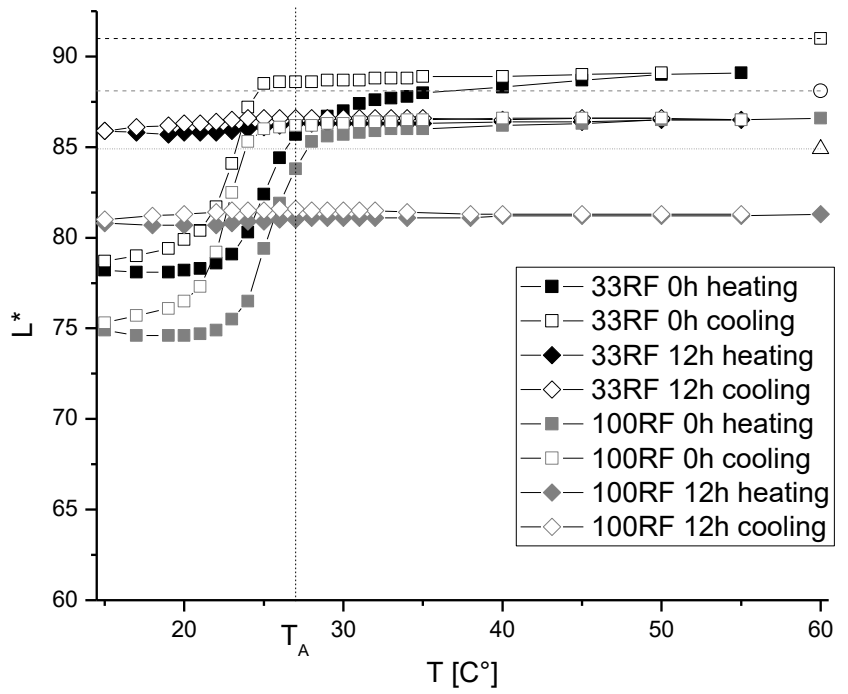

Figure 7: Hysteresis loops of TC27 ink printed on two different papers (original and exposed to UV light for 12h)

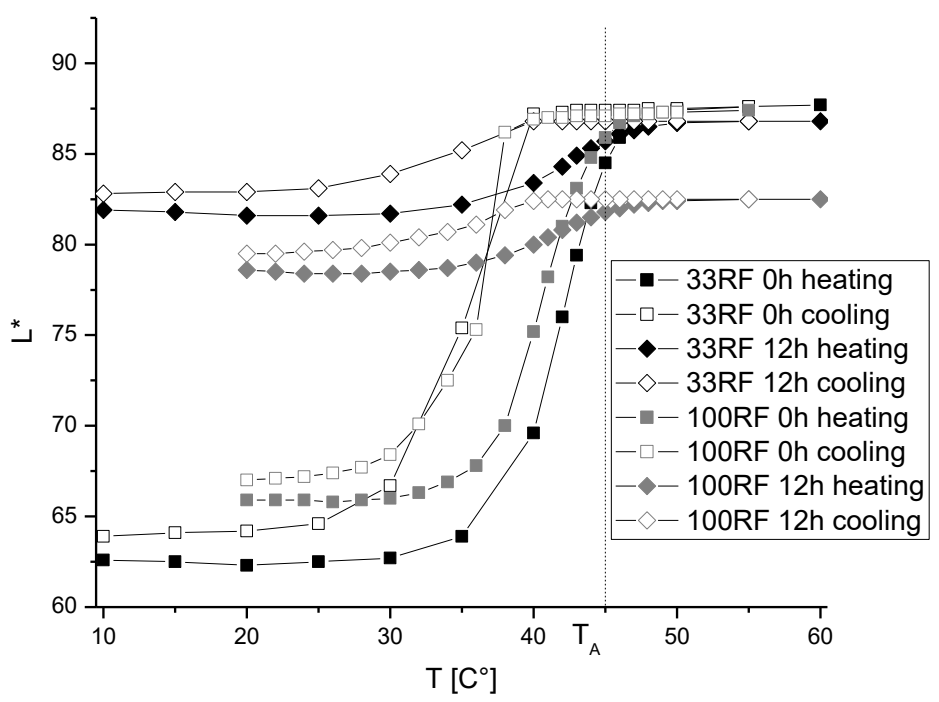

Figure 8: Hysteresis loops of TC45 ink printed on two different papers (original and exposed to UV light for 12h) (open signs).

Figure 7 and 8 shows colour hysteresis of prints on 33RF and 100RF before and after exposed to UV light for 12 hours. These two samples appear differently during the two reversible thermochromic reactions. UV radiation has a great effect on the hysteresis loop. With longer ageing, the hysteresis loop decreases and disappears a bit completely, which means that in this way the dynamic effect of thermochromic inks completely disappears.

Figures 9 and 10 shows the transitons of prints colour from blue to colourless (Figure 9) and from green to yellow (Figure 10). The $a^{*}$ and $b^{*}$ values of prints after 12 hours of ageing are smaller than the initial values. The color change pathway was significantly reduced especially in the TC27 sample on both papers. 


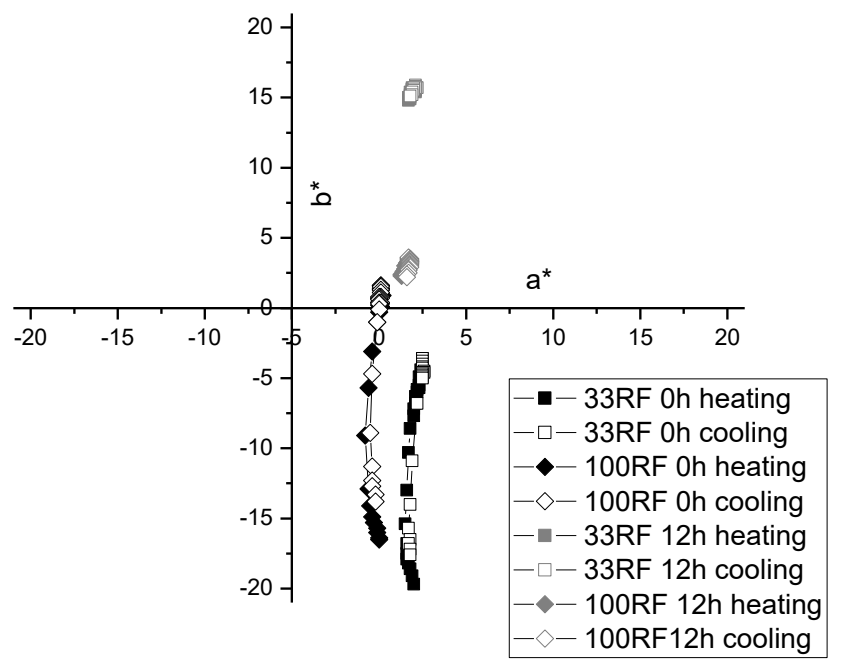

Figure 9: Changing of CIELAB values of TC27 sample in tbe ( $\left.a^{*}, b^{*}\right)$ plane during (solid signs) and cooling (open signs).

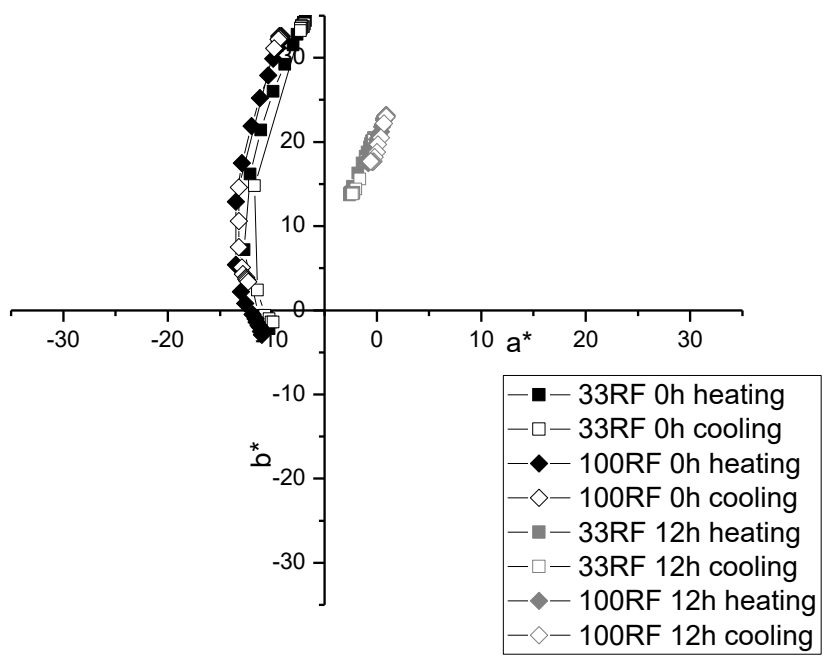

Figure 10: Changing of CIELAB values of TC45 sample in tbe $\left(a^{*}, b^{*}\right)$ plane during heating (solid signs) and cooling

It can be seen from Figure 7 and 9 that the exposure of the sample to accelerated ageing changes the dynamics of discolouration, especially in the thermochromic colour TC27, in which after 12 hours of accelerated ageing the chromism disappears almost completely.

The TC45 sample gave better results than TC27 in terms of accelerated aging, which can be determined from the hysteresis surface in Figure 8 and the CIELAB representation (Figure 10), where it can be observed that the dynamics of color change is present even after 12 hours, although significantly reduced.

Offset inks generally consist of the colorant, the binder, and the additives (catalytic dryers, antioxidants, wax particles and other). The colorant is a hydrophobic organic pigment and the binder consists of alkyd and hard resins. Ink oils can be classified into mineral (mixture of hydrocarbons from petroleum distillates) and vegetable oils (esters) (Pykönen et al, 2018). The mineral oil based inks dries mainly by the absorption into the paper structure while an oxygen-induced free-radical polymerization of unsaturated ink components can occur if the inks contain drying oils or alkyds, resulting in the ink matrix polymerization and crosslinking, while under the influence of oxygen can partly solidify. After printing, the mineral oil-based inks slowly absorb into the pore structure of the paper and it is desired that the oil 
separates from the pigments encapsulated by the binders to obtain sufficient print quality. However, if the ink contains drying oils or alkyds, such as alkyd resin as the binder and vegetable oil as the carrier, oxygen-induced polymerization and cross-linking reactions with unsaturated offset ink components will harden the structure of the ink and strongly bind the ink to the fibers by chemical /or physical means (Kemppainen et al, 2015). Additionally, polar vegetable oils also were found to be less mobile than the non-polar mineral oils (Koivula et al, 2008). Vegetable oils have typically better stability due to higher boiling point when comparing to mineral oils (Pykönen et al, 2018).

Recycled paper is absorbent and ink can penetrate into its structure. while in the case of non absorbent papers (coated, synthetic) the ink binder stays on te paper surface (Vukoje et al, 2017; Vukoje et al, 2018b).

Taking into account all the above menioned facts, it can be concluded that the TC27 ink binder after printing, absorbs into the paper structure, and separates from the TC microcapules, leaving them more "unprotected" to UV irradiation. In the case od TC45, after printing the process of oxipolymerization occurs, forming the polymerized matrix on the top of the paper, making the TC microcapsules more secrue. This results in better stability of TC45 to UV ageing than TC7.
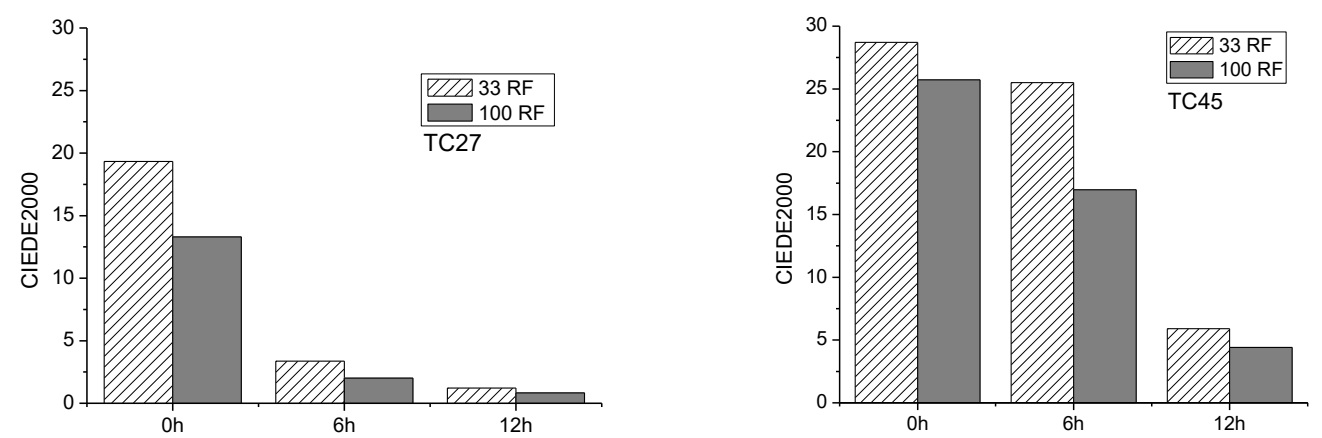

Figure 11: Total colour difference (CIEDE2000) between the lowest and the highest measured temperatures

Figure 11 shows the CIEDE2000 colour difference between the lowest and the highest temperatures to highlight the overall color contrast. A higher CIEDE2000 value represents a larger color change due to the thermochromic reaction. From this, it is evident that thermochromic properties depend more on ink properties and ageing than on the characteristics of the used recycled papers.

\section{CONCLUSION}

In this paper, measurements were performed on two offsets reversible thermochromic printing inks based on leuco dyes of different activation temperatures on papers with $33 \%$ and $100 \%$ of recycled fibre content. UV treatments showed negative effects on the stability and reversibility of the coloured samples. Exposure to UV radiation on the samples shows a decrease in the dynamics of discolouration. The destruction of the thermochromic effect on ageing is greater on TC27 sample. The binder in TC27 inks is mineral oil-based while the binder in TC45 is vegetable-based. This parameter in the ink composition may affect the degree of UV stability. The substrate used in this study showed similar results to studies on some other non-recycled media, indicating that more environmentally friendly substrates can be used as well, in printing with thermochromic inks.

\section{REFERENCES}

[1] Awaja, F., Gilbert, M., Kelly, G., Fox, B., Pigram, P.J.: "Adhesion of polymers”, Progress in Polymer Science 34, 948-968, 2009. doi: 10.1016/j.progpolymsci.2009.04.007.

[2] CEPI, Key Statistics 2016. Brussels, 2017.

[3] Coppola, F., Modelli, A., Strlič, M., Andretta, M., Scagnolari, F.: "Kinetics of degradation of nonrecycled and recycled contemporary paper", Cellulose 25, 5337-5347, 2018. doi: 10.1007/s10570018-1951-8 
[4] Friškovec, M., Kulčar, R., Klanjšek Gunde, M.: "Light fastness and high-temperature stability of thermochromic printing inks", Coloration Technology 129, 214-222, 2013. doi: 10.1111/cote.12020

[5] Gunde, M.K., Friškovec, M., Kulčar, R., Hauptman, N., Kaplanova, M., Panak, O., Vesel, A.: "Functional properties of the leuco dye-based thermochromic printing inks", Proceedings of the Technical Association of the Graphic Arts 2011, (TAGA, USA, 2011), pages 5 -21.

[6] Kemppainen, K., Upola, H., Körkkö, M.: "Ink and dirt behavior in repulping after artificial aging of coldset offset-printed newspapers at different temperatures", Nordic Pulp and Paper Research Journal 30, 527-534, 2015. doi: 10.3183/npprj-2015-30-03-p527-534.

[7] Kibirkštis, E., Kabelkaite, A., Markowski, L., Miliunas, V.: "Microscopic analysis of recycled paper effect on print quality parameters", Microscopy Research and Technique 76, 890-892, 2013. doi: 10.1002/jemt.22243

[8] Koivula, H., Preston, J.S., Heard, P.J., Toivakka, M.: "Visualisation of the distribution of offset ink components printed onto coated paper", Colloids and Surfaces A: Physicochemical and Engineering Aspects 317, 557-567, 2008. doi: 10.1016/j.colsurfa.2007.11.043.

[9] Kulčar, R., Friskovec, M., Hauptman, N., Vesel, A., Klanjšek Gunde, M.: "Colorimetric properties of reversible thermochromic printing inks", Dyes and Pigments 86, 271-277, 2010. doi: 10.1016/j.dyepig.2010.01.014.

[10] Moutinho, M.T., Ferreira, P.J.T., Figueiredo, M.L.: "Paper surface chemistry as a tool to improve inkjet printing quality", BioResources 6, 4259-4270, 2011.

[11] Panák, O., Držková, M., Kaplanová, M.: "Insight into the evaluation of colour changes of leuco dye based thermochromic systems as a function of temperature", Dyes and Pigments 120, 279-287, 2015. doi: 10.1016/j.dyepig.2015.04.022

[12] Pykönen, M., Silvaani, H., Preston, J., Fardim, P., Toivakka, M.: "Influence of plasma activation on absorption of offset ink components into pigment-coated paper", Nordic Pulp and Paper Research Journal 25, 93-99, 2018. doi: 10.3183/npprj-2010-25-01-p093-099.

[13] Vukoje, M., Glibo, R., Kulčar, R., Rožić, M., Vukoje, M., Glibo, R., Kulčar, R., Rožić, M.: "The influence of printing substrate on colorimetric properties of thermochromic offset prints", Acta Graphica 29, 7-14, 2018a. doi: 10.25027/agj2017.28.v29i3.161

[14] Vukoje, M., Miljanić, S., Hrenović, J., Rožić, M.: "Thermochromic ink-paper interactions and their role in biodegradation of UV curable prints", Cellulose 25, 6121-6138, 2018b. doi: 10.1007/s10570018-1970-5.

[15] Vukoje, M., Rožić, M., Miljanić, S., Pasanec Preprotić, S.: "Biodegradation of thermochromic offset prints", Nordic Pulp \& Paper Research Journal 32, 289-298, 2017. doi: 10.3183/NPPRJ-2017-32-02p289-298.

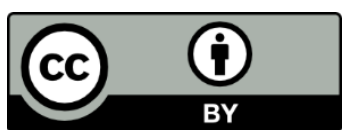

(C) 2020 Authors. Published by the University of Novi Sad, Faculty of Technical Sciences, Department of Graphic Engineering and Design. This article is an open access article distributed under the terms and conditions of the Creative Commons Attribution license 3.0 Serbia (http://creativecommons.org/licenses/by/3.0/rs/). 